HEAT ENGINEERING

\title{
IMPROVING THE THERMAL CHARACTERISTICS OF FURNACES AND THE OPERATING CONDITIONS OF THE LINING BY IMPROVING DIRECT-FLAME-IMPINGEMENT METHODS FOR INTENSIFYING THE HEATING OF METAL
}

\author{
V. G. Lisienko ${ }^{1}$ and E. M. Shleimovich ${ }^{1}$
}

Translated from Novye Ogneupory, No. 6, pp. 23 - 30, June, 2013.

\begin{abstract}
Original article submitted December 5, 2012.
This article discusses Russian research and development of the direct-flame-impingement method of heating and modifications made to this technology abroad in the form of the DFI and Oxy-fuel heating systems. It examines the advantages of these heating methods, especially the sharp reduction in refractories use and the substantial improvement in the service conditions of the furnace lining. Various designs of direct-flame-impingement heating furnaces are presented and aspects of their thermal performance are discussed. It is shown that the thermal efficiency of modern furnaces which employ direct flame heating can reach $65 \%$ and that emissions of nitrogen oxides from these units do not exceed $30 \mathrm{ppm}$ even when the combustion air is preheated. The efficiency of using oxygen in natural-gas-fired heating furnaces is evaluated for different natural-gas prices. Relations are obtained to describe the effect of the degree of oxygen enrichment of the combustion air on the consumption of natural gas and oxygen individually and the consumption of natural gas + oxygen. The cost-effectiveness of using gas-oxygen burners in melting furnaces is also examined.
\end{abstract}

Keywords: heating furnaces, direct-flame-impingement heating, DFI heating technology, Oxy-fuel heating systems, reduction in lining temperature, conservation of refractories, fuel conservation, gain in productivity, emission of nitrogen oxides, natural gas, oxygen.

The method of direct-flame impingement (DFI) for heating flat-rolled products and tubular semifinished products in sectional furnaces - a technology which was developed at the All-Union Scientific Research Institute of Heat Engineering in Metallurgy (VNIIMT) - was first introduced at the Seversky Pipe Plant. It was subsequently also put to practical use at the Pervouralsk New Tube Plant (with the participation of researchers from the Ural Polytechnic Institute under the direction of V. G. Lisienko). Stand tests and commercial trials of DFI were first done in the 1970s with the use of mathematical models, and it was introduced at plants in the Urals beginning in the 1980s $(1-3]$. In addition to the authors of this article, F. R. Shklyar, G. K. Malikov, D. L. Lobanov, V. A. Korshunov, Yu. K. Malikov, Yu. V. Kryuchenkov, and others took part in the development and introduction of DFI. The management and staff of the Seversky Pipe

\footnotetext{
1 Ural Federal University, Ekaterinburg, Russia.
}

Plant and Pervouralsk New Tube Plant provided a great deal of support in the industrial adoption of the technology.

The main features of DFI demonstrate its advantages over traditional heating methods - especially those that use tunnel furnaces - as well as the methods normally used to heat and heat-treat metal in furnaces:

- jets of a previously prepared mixture are burned without the use of burner tunnels and extend into the working volume of the furnace; in this case, the flame impinges directly onto the surface of the semifinished product being heated (Fig. 1);

- rapid and uniform heating of the semifinished product (plate, tube) is achieved by installing uncooled multi-nozzle burners in the furnace lining; the precision-forged nozzles are made of heat-resistant steel;

- the high-velocity discharge of the mixture $(100-300 \mathrm{~m} / \mathrm{sec})$ prevents flashback into the burner, keeps the nozzle from overheating, and ensures that the convective 
heat-transfer coefficient at the surface of the semifinished product is within the range $150-250 \mathrm{~W} /\left(\mathrm{m}^{2} \cdot \mathrm{K}\right)$;

- the simplicity of the design makes it possible to install as many burners as are needed per unit surface of the metal (from 10 to 200 per $1 \mathrm{~m}^{2}$ ) for a wide range of heating conditions, thus optimizing the thermal efficiency of the heating scheme and the environmental indices of the combustion products.

The furnace is compact and has little inertia, the volume of its lining is appreciably smaller in for comparable furnaces (Fig. 2), and its operating conditions have been improved significantly.

DFI furnaces have undergone various changes with the progress from sectional single-channel roller-hearth designs to three-channel units [3-7]. These modifications are shown in Figs. 3 - 6. In the DFI furnace shown in Fig. 5, the burners simultaneously provide for heat recuperation (jet recuperators are installed directly inside the burner housing). They preheat the air to $700^{\circ} \mathrm{C}$ and additionally reduce fuel consumption.

Stand tests, commercial trials, and results obtained from practical use of DFI furnaces have demonstrated their significant advantages over the traditional furnaces used previously. For example, the working volume of a single-channel sectional DFI furnace designed to heat continuous tubes (see Fig. 3) is five times smaller, the volume of the lining is nearly four times smaller, thermal efficiency is twice as great, and the temperature of the lining - which before reconstruction was roughly $1350^{\circ} \mathrm{C}$ - has been decreased by $200-250^{\circ} \mathrm{C}$. This had led to a substantial increase in the life of the lining, lengthened the time between repairs, and protected the metal from being overheated by radiation from the lining in emergency situations.

Before reconstruction, the lining was working at the temperature limit of its standard fireclay refractories and required frequent replacement. When the furnace was shut

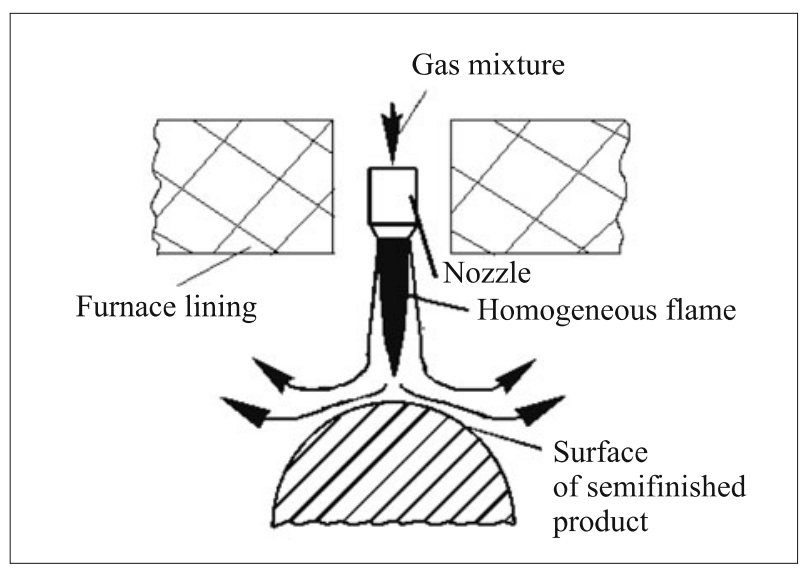

Fig. 1. Diagram of direct-flame-impingement heating (one of the nozzles of the multi-nozzle burner is shown).

down due to an emergency situation, the intense radiant heat flow from the heated lining would cause the tubes to sag on the rollers and even melt. Extracting the tubes without having them burn completely often became impossible, and burning of the tubes inside the furnace caused severe damage to the lining. In a DFI furnace, the metal can easily be reliably protected from overheating by heat radiation from the red-hot lining by cooling the semifinished products with air jets.

After reconstruction of the furnace, the heat loss from cooling of the rollers was reduced by a factor of 1.7 due to the lower temperature of the furnace gases and the lining and the lower value of the coefficient that characterizes heat radiation from the rollers. The DFI furnace rapidly ignites and reaches its operating range from the cold state in $1.3-2 \mathrm{~h}$, the exact time depending on the rate of heating of the lining. Before reconstruction, readying the furnace for operation required a considerable amount of time due to the large volume

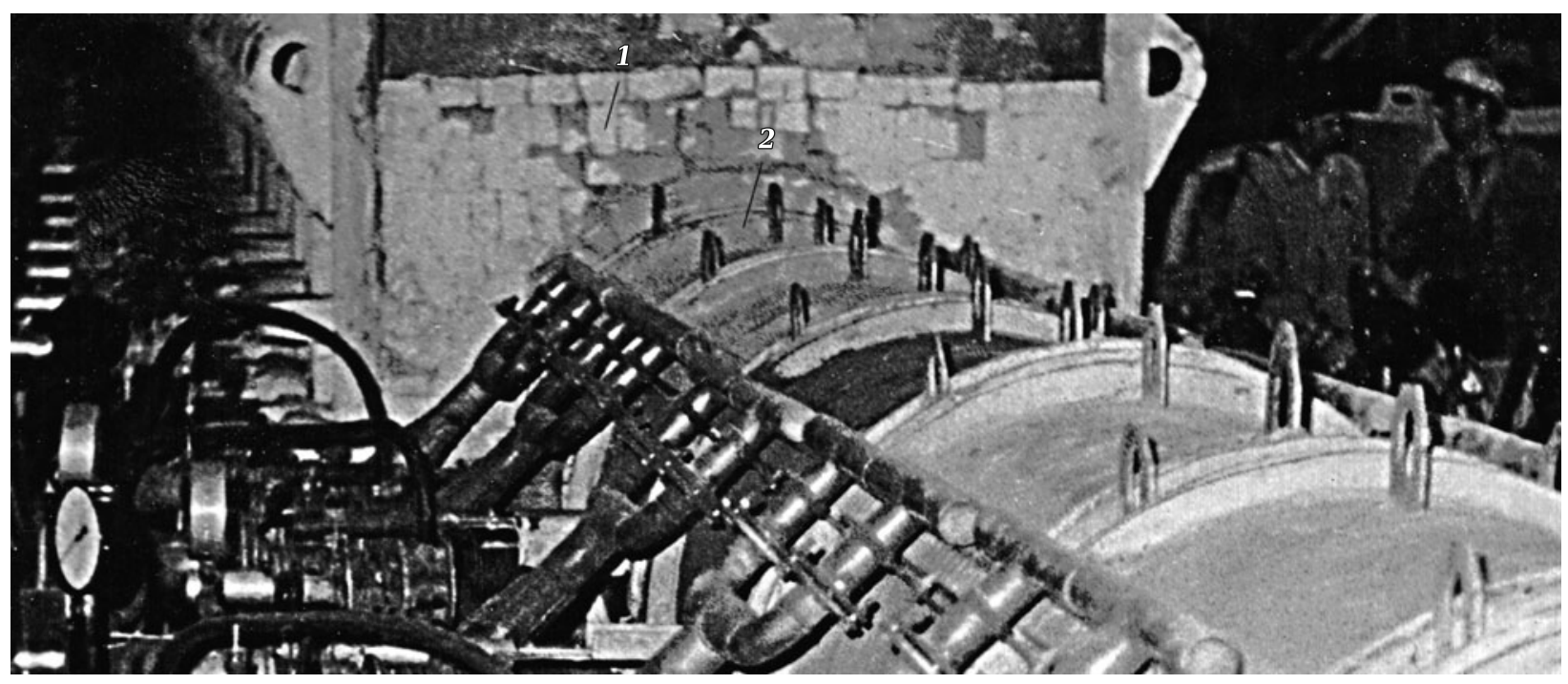

Fig. 2. Reconstruction of a single-channel sectional furnace: 1 ) section before reconstruction; 2 ) DFI-heating section. 


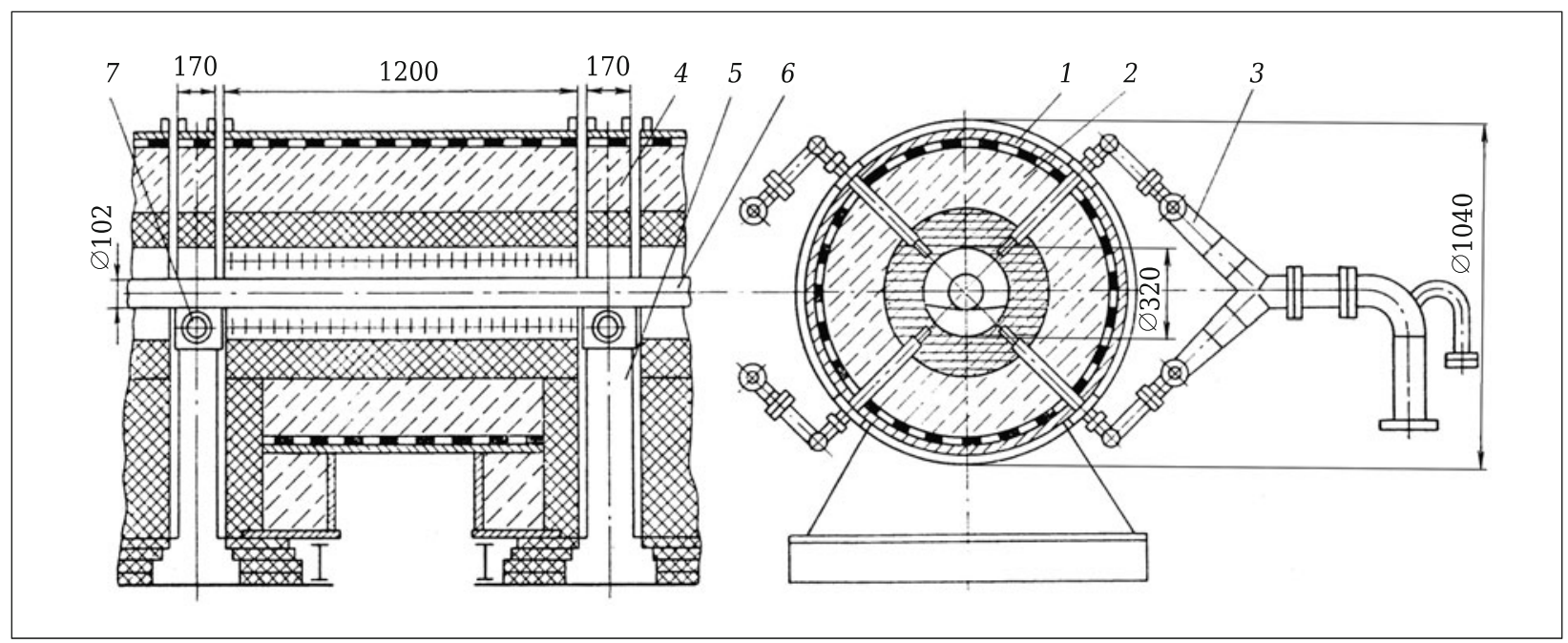

Fig. 3. Cross section of a single-channel DFI furnace: 1 ) housing; 2 ) lining; 3 ) multi-nozzle jet-flame burner; 4 ) cover of tambour; 5 ) gas flue; 6 ) tube being heated; 7) transporting roller.

of the lining (it took $6-8 \mathrm{~h}$ from ignition to until the beginning of charging of the tubes). In the DFI furnace, the required heating of the tubes is assured almost immediately when the furnace transitions to its standard operating regime. As regards the no-load regime, the changeover to the DFI furnace has made it possible and sufficient to keep the temperature of the lining at just $950-1000^{\circ} \mathrm{C}$. As a result, after reconstruction the consumption of comparison fuel decreased by a factor of $1.9-2.2$, the productivity of the furnace rose $15 \%$, and its efficiency increased from 22 to $40-42 \%$.

Mobile tube-type jet recuperators have been used with high-capacity three-channel sectional DFI furnaces (Fig. 4) to heat the air supplied for combustion. Such an approach also sharply reduces the size of the furnace, brings a signifi-

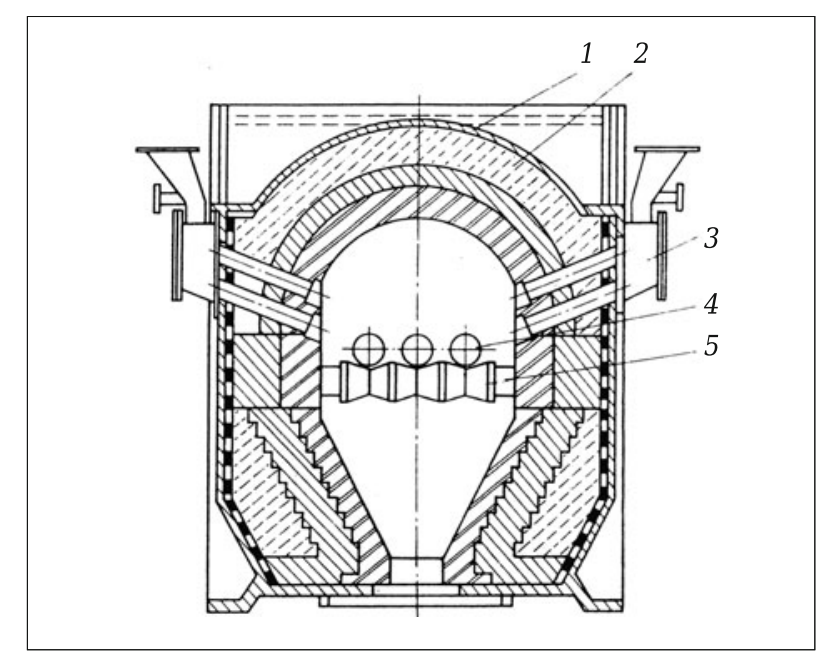

Fig. 4. Design of three-channel furnace with lateral jet-flame heating by a multi-nozzle burner: 1 ) housing; 2 ) lining; 3 ) multi-nozzle burner; 4 ) semifinished product; 5 ) transporting roller. cant savings in refractories, increases the productivity of the furnace, and reduces unit fuel consumption by $25-30 \%$.

It is very important to point out that the transition to DFI furnaces has made it possible to sharply (by a factor of $2-3$ ) reduce emissions of oxides of nitrogen. The quantities of thermal oxides of nitrogen that are formed (by the wellknown mechanism discovered by Ya. B. Zeldovich) should be especially low, since DFI heating sharply reduces the volume of gases formed in the hottest zones of the furnace and lowers furnace temperature as a whole.

Later investigations [8] showed that several known mechanisms of suppressing emissions of nitrogen oxides are realized in DFI furnaces: a reduction in combustion temperature (as a result of intensive heat transfer to the metal being

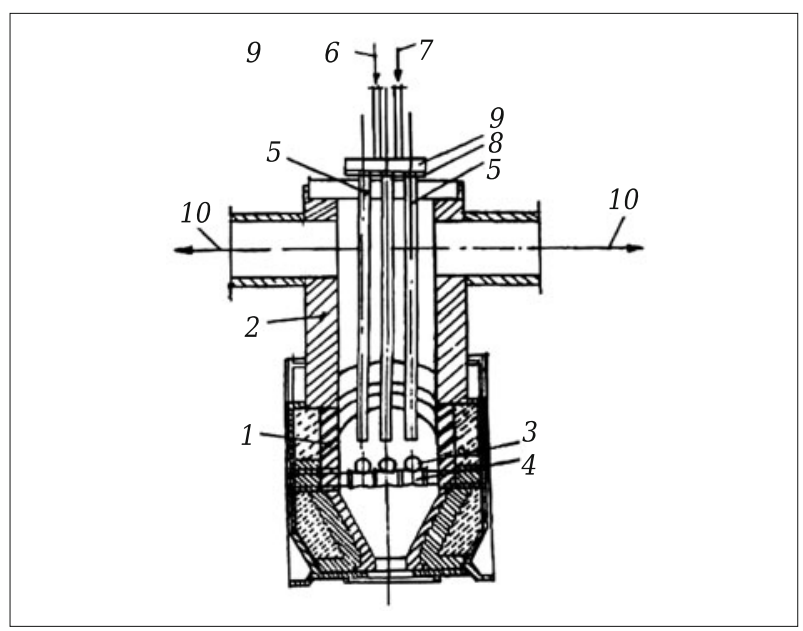

Fig. 5. Sectional three-channel DFI furnace with recuperative jet burners (RJB): 1 ) lining; 2 ) discharge channel; 3 ) tubular semifinished products; 4 ) roller; 5 ) housing of RJB burners; 6 ) gas feed; 7) air feed; 8) gas main; 9) air dust; 10 ) gas flue. 


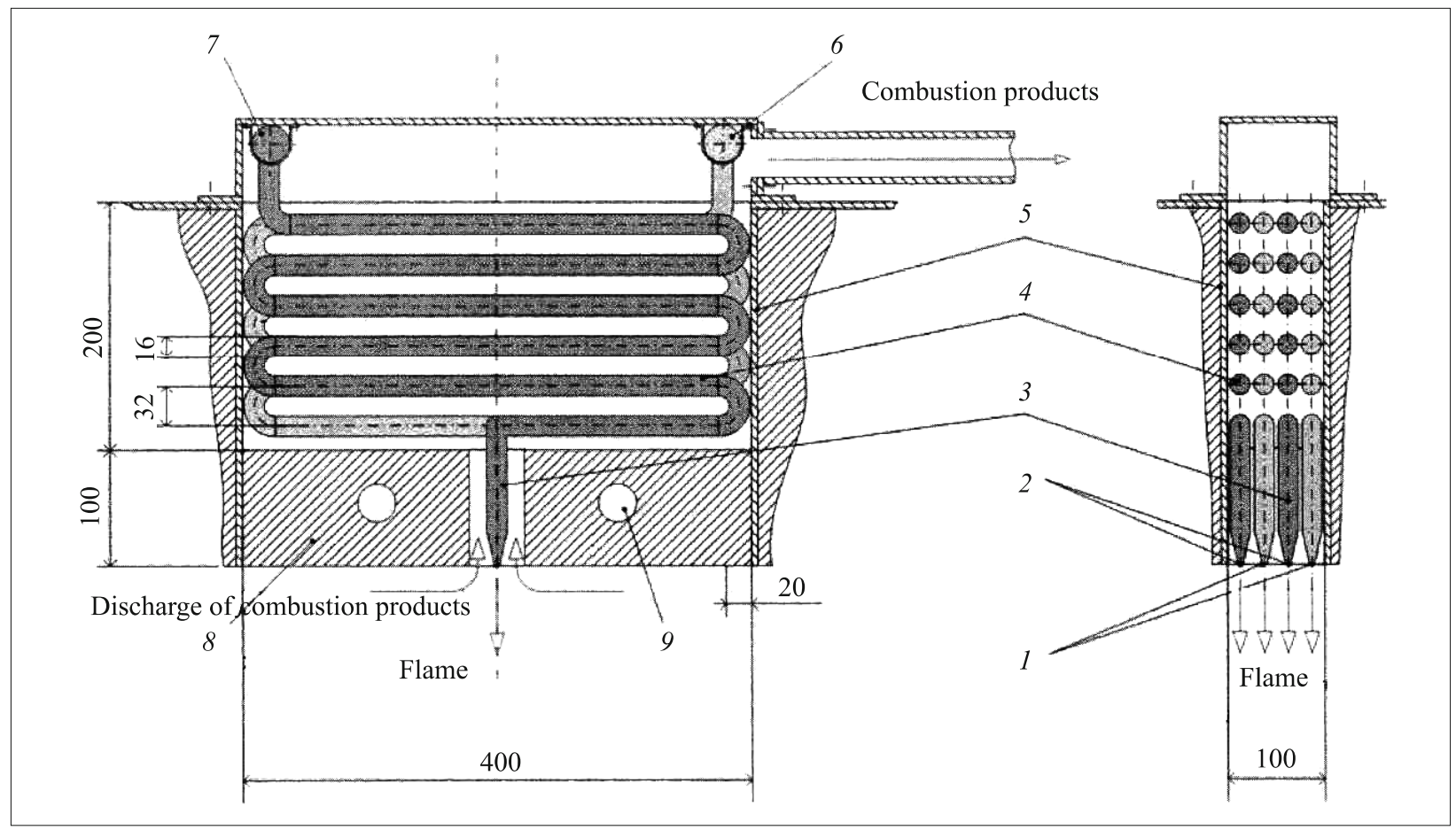

Fig. 6. Recuperative-burner block: 1 ) nozzle for rich gas-air mixture; 2 ) nozzle for lean gas-air mixture; 3 ) nozzle tube; 4 ) loops of the recuperator; 5 ) recuperator chamber; 6 ) main for rich gas-air mixture; 7 ) main for lean gas-air mixture; 8) burner block; 9 ) steel supporting rods.

heated); an increase in the frequency of circulation (the large number of jets and their high velocity); the elimination of locally overheated zones of gas within the working volume of the furnace (due to the forced mixing of the gas and air and the absence of burner blocks). These mechanisms should act together in DFI furnaces to have a combined effect on emissions. It was also determined that oxides of nitrogen are formed mainly by the so-called rapid mechanism in DFI furnaces; emissions of these gases are thus as close to the minimum as possible and are nearly independent of the temperature of the combustion air for the $100-400^{\circ} \mathrm{C}$ range of preheated-air temperatures used in the investigation (Fig. 7).

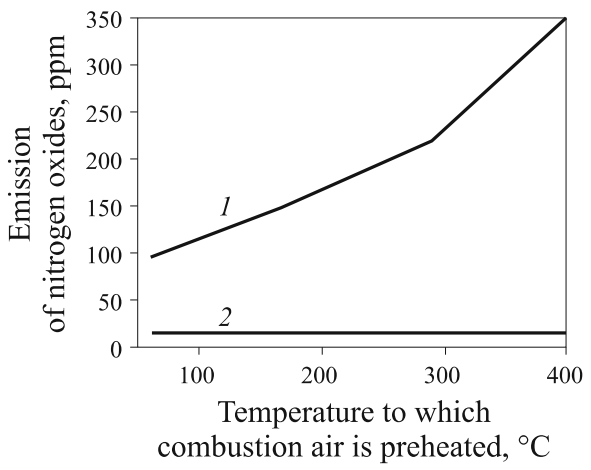

Fig. 7. Dependence of emission of $\mathrm{NO}_{\mathrm{x}}$ on air-preheating temperature: 1 ) conventional tunnel burners; 2 ) DFI burners ( $\left.1 \mathrm{ppm}=10^{-4 \%}\right)$.
A detailed study of features of the thermal performance of DFI furnaces was undertaken jointly by Russian and American specialists on a experimental laboratory furnace (Figs. 8 and 9). R. Viskant, M. Hinkis, J. Wagner, and I. Kurek were among the American scientists that were actively involved in the study.

The furnace was built in the testing shop at the Institute of Gas Technologies in Chicago (U. S.) and was equipped with state-of-the-art, often unique instruments to measure the flow rate, temperature, and composition of the combustion products and other parameters. Natural-gas consumption

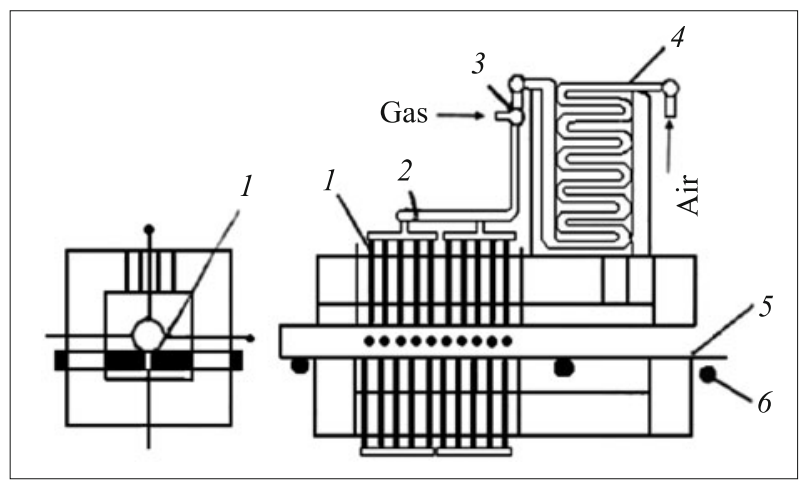

Fig. 8. Diagram of the DFI Lab Furnace: 1) premix burners; 2 ) main; 3 ) mixer; 4 ) recuperator; 5 ) water-cooled calorimeter; 6 ) rollers (a variant in which a flat semifinished product was heated was also studied). 


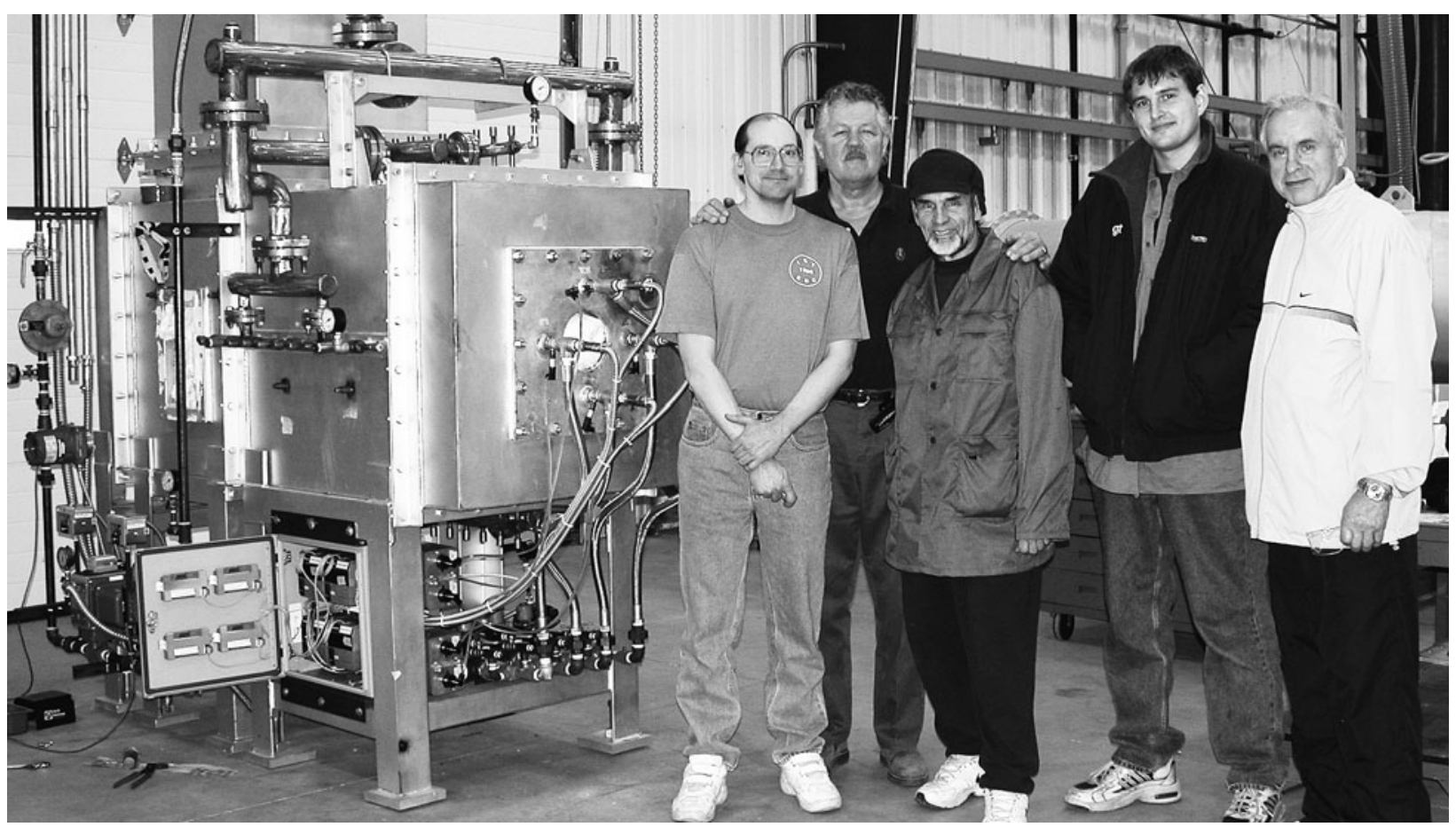

Fig. 9. "Integrated team" of Russian and American researchers next to an experimental direct-flame-impingement heating furnace (Chicago, U.S.): first from the left — V. G. Lisienko; third from the left — G. K. Malikov.

reached $30 \mathrm{~m}^{3} / \mathrm{h}$ and the air was preheated to $650^{\circ} \mathrm{C}$. The work done on the furnace confirmed previous results showing the advantages of DFI and yielded additional new information. In particular, the thermal efficiency of the furnace reached $65 \%$ and emissions of nitrogen oxides did not exceed $30 \mathrm{ppm}$ even when the air was preheated. This figure compares favorably to the $240-250 \mathrm{ppm}$ emission level seen on standard furnaces $[4-5]$.

Before and during the experiments, we performed 3D model studies of the temperature, rate, and concentration characteristics of the flames and elements of the experimental furnace's working space. For the most part, the results ob-

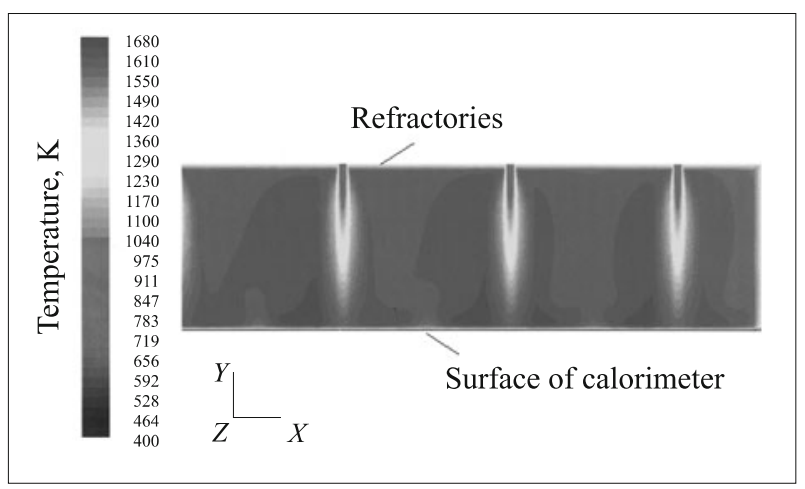

Fig. 10. Model temperature fields of the experimental DFI furnace. tained in these studies were substantiated by the experimental data (Figs. 10 and 11).

In the course of designing the experimental furnace and conducting the experiments in the U.S., the acronym DFI Direct Flame Impingement - which we proposed was used for the English translation of the heating method employed in the investigation [4]. The American scientists were in agreement on this, and the DFI acronym has since come into standard use abroad as the name of the technology [5,9]. For example, Fig. 12 shows a DFI furnace installed at one American plant to heat large aluminum semifinished products,

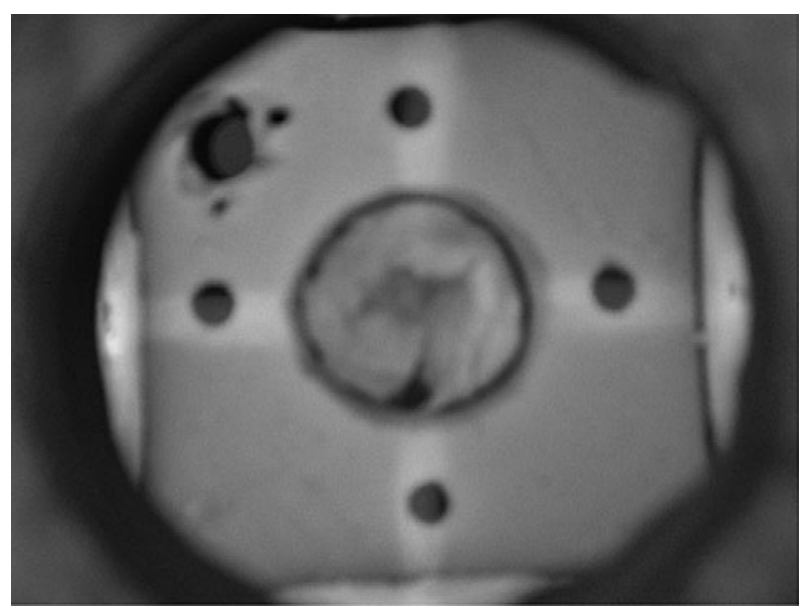

Fig. 11. Jet zone of laboratory furnace with four jet flames (photograph taken with a cobalt blue filter). 
while Fig. 13 shows a roller-hearth (high-speed-heating) DFI furnace at a factory in Germany.

Thus, the improvements made to DFI-based methods have led to the construction and use of DFI furnaces in the U.S., Germany, Sweden, and other countries. However, in a number of cases a distinctive feature of the actual technology that is employed (and this has been noted in the literature) is the use of oxygen in the burners. Thus, the term Oxy-fuel has been added to the DFI acronym.

Several of the survey articles that been written on DFI Oxy-fuel heating technology have appeared in publications of the Gas Institute of the National Academy of Sciences of the Ukraine $[9,10]$. To cite one example, it has been noted that DFI Oxy-fuel technology (with the flame impinging directly on the metal) is being used in heating furnaces and on furnaces used to heat-treat steel strip (Germany, Sweden, South Korea, and German-Swedish joint ventures organized by the company "Linde Group")

It should be emphasized that the use of oxygen in DFI Oxy-fuel furnaces makes it possible to significantly increase the productivity of the furnace and reduce fuel consumption. The use of oxygen has become quite common abroad in glassmaking furnaces and for heating in various other types of furnaces. It has been reported that oxygen is being used in rotary furnaces and continuous furnaces to enrich the combustion air, with the concentration of oxygen ranging from 5 to $100 \%$. For example, the use of oxygen in heating furnaces by the Linde Group has reduced unit fuel consumption by $63 \%$, lowered emissions of hazardous substances with the outgoing gases by $74 \%$, and shortened heating time by a factor of $1.7-2.0$. Other reports have communicated reductions in scale formation (by 76\%), a decrease in the size of the burners and the furnace as a whole, less noise generation, lowering of the temperature of the furnace's outer shell, and reductions in wear of the refractories and the volume of repair work needed. The capital investment was recouped in two years in these cases $[9,10]$.

However, in Russia the use of oxygen is still limited mainly to high-temperature melting furnaces [11, 12].

In our view, it would be best to analyze the cost-effectiveness of using oxygen in melting furnaces and heating furnaces under conditions that reflect the existing differences in the prices for electric power, natural gas, and oxygen. As is known, natural-gas prices in Russia are subsidized. However, these prices too have gradually been rising recently. They have gone from roughly $\$ 20$ (U.S.) to $\$ 110$ (3300 rubles) per $1000 \mathrm{~m}^{3}$ of natural gas. The figure $\$ 120$ (3600 rubles) can be taken as the price of $1000 \mathrm{~m}^{3}$ of oxygen and $2.7-3.0$ rubles can be taken as the cost of $1 \mathrm{kWh}$ of electric power. Abroad, the price of natural gas per $1000 \mathrm{~m}^{3}$ can reach $\$ 350$ or more. For example, Ukrainian prices per $1000 \mathrm{~m}^{3}$ are $\$ 600$ for natural gas and $\$ 150$ for oxygen.

We will make a preliminary estimate of the cost-effectiveness of using oxygen in heating furnaces when natural gas is at different prices. The cost of other factors connected with the use of oxygen will not be considered in making the

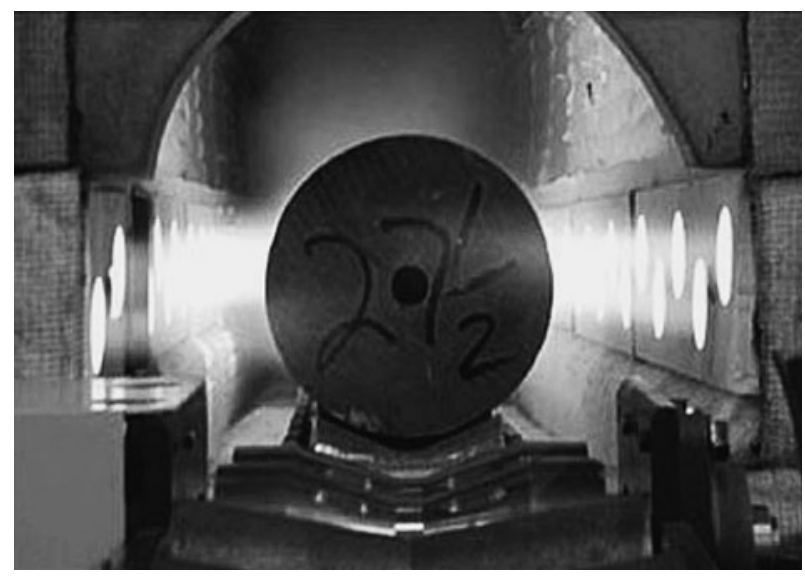

Fig. 12. DFI furnace for heating aluminum billets prior to extrusion (U.S.).

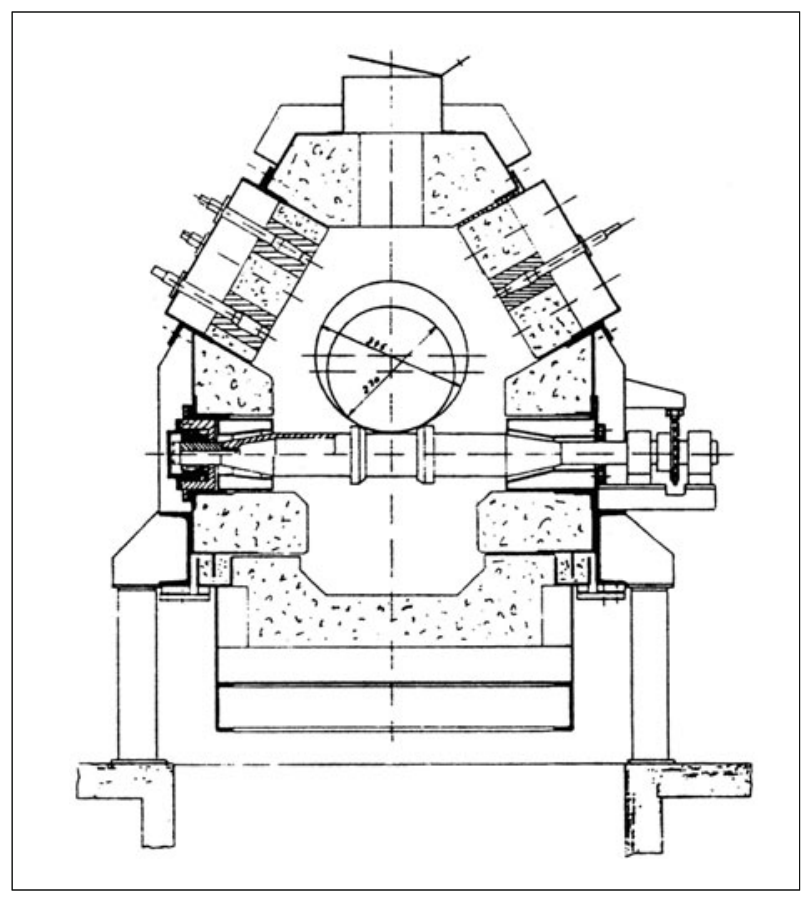

Fig. 13. Roller-hearth DFI furnace for the high-speed heating of semifinished products made of nonferrous metals (Germany).

estimate. As regards heating furnaces, the economic aspects of enriching air with oxygen can be discerned fairly well by examining how the degree of enrichment of combustion air with oxygen affects the consumptions of natural gas and oxygen and their combined consumption (Fig. 14). In evaluating the gas/oxygen ratio, we of course proceeded on the basis of the stoichiometric reaction

$$
\mathrm{CH}_{4}+2 \mathrm{O}_{2}=\mathrm{CO}_{2}+2 \mathrm{H}_{2} \mathrm{O} \text {, }
$$

It follows from this reaction that the combustion of one volume of natural gas requires two volumes of oxygen. Cal- 


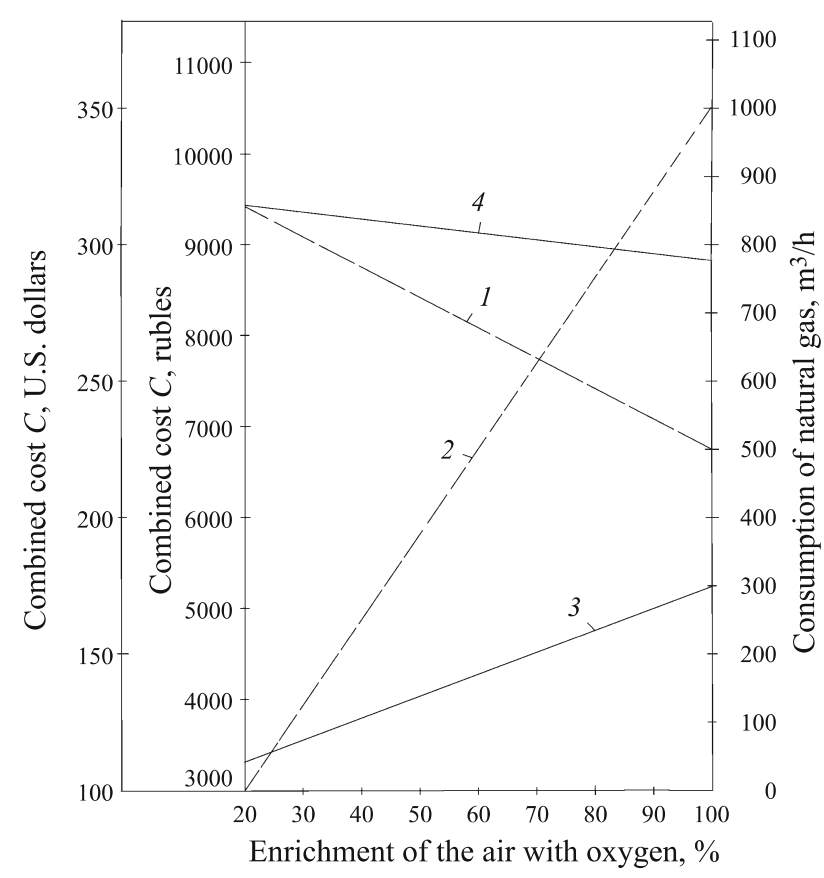

Fig. 14. Relationship between the consumption of natural gas $G(1)$ and oxygen (2) and the combined cost $C$ of natural gas + oxygen at a natural-gas price of 3300 rubles or $\$ 110$ (U.S.) (3) and 10500 rubles or $\$ 350$ (4). The calculations were performed for a natural-gas consumption $G=1000 \mathrm{~m}^{3} / \mathrm{h}$ and operation of the furnace on air. Thermal efficiency doubles when the oxygen enrichment of the combustion air is increased from 21 to $100 \%$.

culations were performed for a tentative natural-gas consumption of $1000 \mathrm{~m}^{3} / \mathrm{h}$ (which is quite realistic for a number of heating furnaces and units).

We took $\$ 100$ (U.S.) (3300 rubles) as the price of $1000 \mathrm{~m}^{3}$ of natural gas in Russia and $\$ 350$ (10500 rubles) as its price abroad. The price used for oxygen was the same for Russia and abroad - $\$ 120$ (3600 rubles) per $1000 \mathrm{~m}^{3}$.

According to data from foreign sources that was analyzed in detail in [9], the thermal efficiency of furnaces heated by the Oxy-fuel method can be as much as doubled by enriching the combustion air with oxygen. We used this factor in our calculations.

It follows from Fig. 14 that given the relatively low (Russian) price for natural gas, enrichment of the combustion air with oxygen increases operating costs by a substantial amount - a factor of more than 1.5 (line 4). At the same time, the opposite is seen when the cost of natural gas is high and combustion air is enriched with oxygen; expenditures on natural gas + oxygen decrease, although the reduction is not as substantial $-20 \%$ in the case we are examining.

Of course, the above calculation did not account for such important factors as the increase obtained in productivity (which according to [10] is $30-100 \%$ when Oxy-fuel heating is used). This consideration weighs quite heavily in favor the oxygen enrichment of combustion air. Added to this are the other potential advantages, which include the possibility of reducing the size of the furnace and saving refractories and metal in the construction of pipelines and auxiliary equipment (recuperators, regenerators) for heating the oxidant. No qualitative changes in the situation depicted in Fig. 14 can be expected in Russia in light of the current price of natural gas, especially in view of the substantial capital investment that would be needed to build oxygen plants. The use of oxygen in heating furnaces in Russia would probably become economically attractive if the price of natural gas rises to above $\$ 200-\$ 220$ per $1000 \mathrm{~m}^{3}$.

The situation is completely different in regard to the heat-engineering of melting furnaces. For example, if arc furnaces are supplied with natural gas through gas-oxygen burners at a rate of $30 \mathrm{~m}^{3} / \mathrm{h}$, the amount of electric power which is equivalent to the heat that is generated will be $296.8 \mathrm{~kW}$. Taking 3600 rubles per $1000 \mathrm{~m}^{3}$ for the price of oxygen and 3300 rubles per $1000 \mathrm{~m}^{3}(\$ 110)$ for the price of natural gas, we find that the equivalent price of the electric power which is replaced ( 2.9 rubles per $\mathrm{kWh}$ ) will be increased by a factor of 2.54. For a natural-gas price of 10500 rubles per $1000 \mathrm{~m}^{3}$, this difference will be smaller but will still be impressive (an increase by a factor of 1.51).

There is still one other extremely important circumstance that distinguishes high-temperature melting furnaces. Heat-transfer efficiency in these furnaces $\eta_{\mathrm{f}}$ is equal to [13]:

$$
\eta_{\mathrm{f}}=\theta_{\mathrm{t}} \eta_{\mathrm{t}}
$$

where $\theta_{t}$ is the initial heating factor; $\eta_{t}$ is the direct heattransfer efficiency.

The quantity

$$
\theta_{\mathrm{t}}=\frac{T_{2}^{\prime}-T_{1}^{\prime}}{T_{2}^{\prime}-T_{0}},
$$

where $T_{2}{ }^{\prime}$ is the temperature of the gases at the inlet of the working space; $T_{1}{ }^{\prime}$ is the temperature (initial) of the material being heated or melted; $T_{0}$ is the ambient temperature.

With allowance for the higher value of $T_{1}{ }^{\prime}$ for melting furnaces compared to the corresponding value for heating furnaces, it follows from Eqs. (2) and (3) that the heat-transfer efficiency of melting furnaces will be markedly lower for the same given value of $\eta_{\mathrm{t}}$.

For example, in steelmaking furnaces this quantity $T_{1}{ }^{\prime} \approx 1500-1600^{\circ} \mathrm{C}$, and when the temperature $T_{2}{ }^{\prime}=2000^{\circ} \mathrm{C}$ the value of

$$
\theta_{\mathrm{t}}=\frac{2000-1600}{2000-20}=0.202
$$

i.e. an increase in the temperature of the metal is accompanied by an equal decrease in direct heat-transfer efficiency $\eta_{t}$ - which is usually also significantly less than unity.

As a result, to increase heat transfer and, thus, thermal efficiency, it is necessary to use every means possible to in- 
crease direct heat-transfer efficiency. This can be done by raising the temperature of the heat-transfer medium $T_{2}{ }^{\prime}$, which in turn is accomplished by using gas-oxygen burners in melting furnaces. Having a hotter heat-transfer medium makes the use of such burners more cost-effective in the fuel-oxygen context.

\section{CONCLUSION}

The development and introduction of the efficient method of direct-flame impingement (DFI) was made a priority in Russia, and now this technology has come into wide use abroad. The method ensures a reduction in the size of furnaces and auxiliary units, brings a significant savings in refractories, reduces fuel consumption and the emission of oxides of nitrogen, and increases the productivity of furnaces.

Oxygen has recently come into wide use abroad to heat metal. Thus, the DFI method is now more likely to be referred to by the acronym KFI Oxy-fuel.

We discussed the role of the price of natural gas in evaluating the cost-effectiveness of using oxygen in heating furnaces: the use of oxygen in a fuel-oxygen system is inexpedient when the price of the gas is relatively low.

As regards melting furnaces, employing natural gas as a substitute for part of the electric power which is normally needed is cost-effective whether the natural-gas price is high or low.

\section{REFERENCES}

1. USSR Author's Certificate No. 726400. Continuous Furnace for the High-Speed Heating of Metal. G. K. Malikov, F. R. Shklyar, D. L. Lobanov, et al. Sub. 01.06.77; Publ. 05.04.1980.

2. G. K. Malikov, F. R. Shklyar, V. A. Korhsunov, et al., "Operation of a direct-flame-impingement heating furnace in the line of an electric-welded pipe mill," Stal', No. 7, 80 - 82 (1983).
3. V. G. Lisienko, G. K. Malikov, Yu. K. Malikov, et al., "Effectiveness of using direct-flame-impingement heating in industrial furnaces," Stal', No. 6, 45=48 (1996).

4. W. G. Lissijenko, S. N. Guschtschin, G. K. Malikow, et al., "Verallgemeinerung der Erfahrungen bei dem Einsatz der Direkt-Flammen-Erwarung von Metall in Industrieofen," Gaswarme International, 50(5/6), 229 - 235 (2001).

5. G. K. Malikov, V. G. Lisienko, Yu. K. Malikov, et al., "Mathematical modeling of direct flame impingement heat transfer," Proc. IMECE 2006. ASME International Mechanical Engineering Congress and Exposition, Chicago, IL, U.S. IMECE, 2006, 13472.

6. V. G. Lisienko, Ya. M. Shchelokov, and M. G. Ladygichev, Fuel - Efficient Combustion, Management, and Industrial Use: Handbook, Vol. 2, Teplotekhnik, Moscow (2004).

7. V. G. Lisienko, Improvement and Rationalization of Energy-Intensive Technologies and Production Processes (integrated energy-environmental analysis: theory and practice), Vol. 1, Teplotekhnik, Moscow (2010).

8. G. K. Malikov, V. G. Lisienko, K. Yu. Malikov, et al., "Calculation of the emission of oxides of nitrogen during the combustion of natural gas in industrial burners," Stal', No. 2, 91-96 (2002).

9. B. S. Soroka, "Combustion systems and heat-recovery equipment of industrial furnaces: current status and international trends," Energotekhnologii i Resursosberezhenie, No. 2, 54-68 (2012).

10. I. P. Karp, A. N. Zaivyi, E. P. Matsevoi, et al., "Use of oxygen and oxygen-enriched air in heating furnaces, soaking pits, and stands used to heat steel-pouring ladles," Ibid. No. 3, 18-28 (2012).

11. A. V. Grechko, "Use of natural gas and oxygen in pyrometallurgy and power engineering," Promysh. Energ., No. 11, $41-48$ (2003).

12. A. V. Savin, V. E. Nikol'skii, and D. V. Vokhnintsev, "Speeding up refining in arc steelmaking furnaces," Glavnyi Energetik, No. 7, $45-48$ (2012).

13. V. G. Lisienko, Ya. M. Shchelokov, and M. G. Ladygichev, Selected Readings on Energy Conservation [in Russian], Vol. 1, Teplotekhnik, Moscow (2002). 